\title{
Dangers and Strangers: Pathogenic threat, FeAR, AND PERCEIVED VULNERABILITY DO NOT PREDICT ETHNOCENTRIC ORIENTATIONS DURING THE COVID-19 PANDEMIC IN EUROPE
}

\author{
Stephanie J. Eder'1, Michal M. Stefanczyk2, Michał Pieniak ${ }^{2}$, Judit Martínez-Molina ${ }^{3}$, Jakub \\ Binter ${ }^{4,5}$, Ondra Pešout ${ }^{6}$, Patrick Smela ${ }^{1}$, Frank Scharnowski ${ }^{7,8,9,10}$, David Steyrl7,8 \\ 1 Department for Basic Psychological Research and Research Methods, University of Vienna, Austria \\ 2Institute of Psychology, University of Wroclaw, Wroclaw, Poland \\ 3Faculty of Psychology, Universitat de Barcelona, Barcelona, Catalunya, Spain \\ ${ }^{4}$ Department of Philosophy and History of Science, Charles University, Prague, Czech Republic \\ 5Department of Social and Economic Studies, Jan Evangelista Purkyne University, Usti nad Labem, Czech Republic \\ 6Department of Psychology, Jan Evangelista Purkyne University, Usti nad Labem, Czech Republic \\ 7Department of Cognition, Emotion, and Methods in Psychology, University of Vienna, Austria \\ 8Department of Psychiatry, Psychotherapy and Psychosomatics, Psychiatric Hospital, University of Zürich, Switzerland \\ ${ }^{9}$ Neuroscience Center Zürich, University of Zürich and Swiss Federal Institute of Technology, Zürich, Switzerland \\ 10Zürich Center for Integrative Human Physiology (ZIHP), University of Zürich, Switzerland
}

Stephanie.eder@univie.ac.at

\begin{abstract}
Previous research has postulated effects of environmental stress on ingroup/outgroup thinking: The higher the pathogenic risk and the perceived vulnerability to it, the higher the ethnocentric orientation. Here, we examine ethnocentric orientations in Austria, Poland, Spain, and the Czech Republic in spring 2020, as the spread of the novel coronavirus was on the rise and lockdown measures were introduced throughout Europe. Critically, these countries were affected differentially by the spread of SARS-CoV-2 and COVID-19 mortality. Participants completed questionnaires assessing identification with all humanity, attachment style, and perceived vulnerability to disease at the beginning and end of the first European curfews. Additionally, they answered questions regarding their social interactions and personal consequences of the crisis. To investigate the relationship between these variables and ethnocentrism, we trained two types of machine-learning models to predict ethnocentrism based on the complex interplay of interpersonal variables (psychological traits, interpersonal interactions) and environmental conditions (economic threats, local mortality, viral spread, lockdown measures). We found that identification with all humanity in relation to narrower ingroups and perceived infectability did not systematically change over the course of the first European lockdowns, whereas we observed a slight decrease in germ aversion. Importantly, none of our models could predict any inter-individual differences in identification with narrower versus wider groups based on environmental, psychological, social, and demographic variables. Our results indicate that environmental variables connected to pathogenic and economic threat, perceived vulnerability and other psychosocial variables, all do not contribute to predicting ethnocentric orientations. Cumulatively, our results do not support the hypothesis that higher pathogenic and environmental threat predicts identification with narrower ingroups. Our findings are discussed in the context of the open debate related to the influence harsh environments on group psychology, and might inspire further research on this topic during this unprecedented global pandemic.
\end{abstract}

Keywords: Identification with all Humanity, Behavioral Immune System, Pathogens, In-group/outgroup, COVID-19 


\section{INTRODUCTION}

\section{A pandemic, pathogens, and political orientations}

In spring 2020, the spread of the novel coronavirus SARS-CoV-2 throughout Europe not only presented a medical and psychological stressor, but also brought about a host of newly introduced, unprecedented societal and governmental regulations that emphasize the threat of social contacts and the importance of cleanliness.

Both the medical threat and the abrupt societal changes can have a psychological impact that may reach political dimensions. For example, Karwowski et al. (2020) show that merely activating thoughts on COVID-19 alters political opinions, supporting claims of the parasite model of democratization (Thornhill et al., 2009). This model states that liberal viewpoints and actions, such as women's rights and engaging in casual sex, positively covary with low pathogen threat. While it has been argued that sexual behavior mediates the relationship between conservatism and pathogen avoidance (Tybur et al., 2015), Thornhill and colleagues (2009) propose that the link between stricter cultural norms and pathogenic threat is ethnocentrism. Ethnocentrism is possibly best described as the tendency to build stronger ingroup-ties, identify with narrower ingroups, and hold negative biases towards out-groups (cf. Brown, 2004, Cashdan, 2001, Pettigrew, 2004). Fincher and Thornhill (2012) have proceeded to associate stronger ingroup-ties with pathogenic pressure over different cultures, although Currie and Mace (2012) critique the proposed causal mechanism of this parasite-stress theory of sociality.

In support of the view that ethnocentrism accounts for the effect of higher pathogenic on cultural norms, various studies have linked inter-individual differences in xenophobia and racism to pathogen disgust and perceived vulnerability to disease (Faulkner et al., 2004; Navarrete \& Fessler, 2006). Seemingly, fearing members of another group might be an overgeneralization of the behavioral immune system's tendency to avoid contact with novel pathogens (Schaller \& Park, 2011). Consistent with this, the strongest correlate between conservatism and disgust sensitivity seems to be the concern about interpersonally transmitted diseases (Inbar et al., 2012), and reminders of physical cleansing increase conservative attitudes and harsher moral judgements (Helzer \& Pizarro, 2011). Similarly, Makhanova et al. (2019) show that artificial media reports about a flu epidemic activate ingroup-binding values, where germ aversion additionally correlates with such moral beliefs.

However, some of these situational findings have not been replicated (Burnham, 2011) and are widely debated (Landy \& Goodwin, 2015; Schnall et al., 2015). Similarly, an increasing body of literature investigating societal effects of environmental conditions does not support the influence of pathogen stress on attitudes towards ingroups and outgroups (Currie \& Mace, 2012; Hadley \& Hruschka, 2017; Van de Vliert \& Postmes, 2012), and insufficient control for other factors has been criticized (Ross \& Winterhalder, 2016). Instead, more recent work has linked material insecurity towards ingroup bias and xenophobia (Hadley \& Hruschka, 2017): If an individual's existential security is threatened, tight connections with narrow ingroups might be an important safety net (Inglehart et al., 2006), at least in societies where there is little 'impartial' governmental aid (Hruschka et al., 2014).

Indeed, evolutionary game theory and agent-based models have shown that particularly under conditions of collective threats, cooperation - albeit costly to the individual - is essential within groups and emerges faster in 'tight' societies (Nowak, 2006; Pan, et al., 2020). As such, cooperative norms tend to appear jointly with strict cultural norms (Roos et al., 2015). However, Tybur and colleagues (2016) found that while pathogen threat might relate to tight ingroup connections, this does not in relation affect negative attitudes towards outgroups. Thus, current evidence suggests that the higher the external threat, the more conservative the cultural behavior. 
Yet, it is unclear if this relationship can indeed be attributed to ethnocentric orientations as proposed by Thornhill and colleagues (2009), and if pathogenic threat specifically plays a causal role as opposed to other factors (cf. Hruschka \& Henrich, 2013; Van de Vliert \& Postmes, 2012).

\section{Ethnocentric orientations}

Ethnocentrism has been called a 'human universal' (Brown, 2004), and reliably appears even in model simulations where no kind of ingroup favoritism is initially predetermined (Hammond \& Axelrod, 2006). Nevertheless, the measured variables associated with such tendencies differ widely throughout the body of literature. For example, the term ethnocentrism has been used to describe positively biased attitudes towards narrower ingroups (Hammond \& Axelrod, 2006), a sense of ingroup superiority (American Ethnocentrism Scale, Neuliep \& McCroskey, 1997; Pettigrew, 2004), 'ethnic loyality' and the 'consciousness of belonging together' (Lang, 1995, as cited in Cashdan, 2001), or conversely as xenophobic or racists attitudes (Manitoba Ethnocentrism Scale, Altemeyer, 1996; Hamer et al., 2019) or behaviors (Hammond \& Axelrod, 2006) towards non-allied groups. On the other hand, multiple studies show that a strong loyalty towards a narrower group and hostility towards outgroups do not necessarily go hand in hand (Cashdan, 2001), and Brown (2004) considers racism and nationalism as an exaggerated form of ethnocentrism rather than a defining part of it. Possibly, the variety of definition and measures accounts for some parts of the contradictory findings in this field, where a measure capturing the relation of a person's perceived affiliation with ingroups versus outgroups might present a more stable measure (cf. Navarrete \& Fessler, 2006).

The COVID-19 pandemic has increased xenophobic attitudes in Europe (Zhai \& Du, 2020), and reminders of the viral threat have been shown to provoke a shift towards more conservative attitudes (Karwowski et al., 2020; Makhanova et al., 2019). These findings suggest a shift away from identification with outgroups, and towards narrower social units. On the other hand, this world-wide crisis also focused the world's attention on the one common problem of containing the virus independent of culture and borders. These aspects may increase identification with all humanity, counteracting effects predicted by the above theories and increasing identification with groups beyond national borders. Critically, however, environmental circumstances interact with psychological variables. A prediction of ingroup/outgroup identification must therefore not only take into account features of the current environment, but also psychological traits and social circumstances. For example, activation of secure attachment patterns heightens tolerance towards outgroup members (Mikulincer \& Shaver, 2001). Another factor might be a person's perceived vulnerability (cf. Inbar et al., 2012), and how vulnerable their health status is. Thus, the interindividual variation in identification with ingroups and outgroups might depend on the complex interaction between environmental influences and multiple psychological variables.

\section{The present study}

Here, we investigate ethnocentric orientations during the COVID-19 pandemic in four European countries. Our target measure is identification with narrower ingroups such as nation and community in relation to all humanity, as measured by the Identification with all Humanity Scale (McFarland et al., 2012), which has been shown to correlate with measures of racist and xenophobic attitudes at medium effect sizes, and with conservative and right-wing authoritarian political attitudes at low effect sizes (Hamer et al., 2019).

We investigate i) if this identification changed over the course of the first lockdown in Europe in Spring 2020 and ii) the predictive value of both external variables such as pathogen threat and 
material insecurity, as well as psychological and social variables. To do so, we fit linear and nonlinear machine-learning models aiming to predict inter-individual variation in identification with all humanity. These models can capture potentially complex interaction between different input variables (including if-then decision structures) and have previously been shown to make accurate predictions of psychological constructs in such samples (Eder, Steyrl, et al., 2021; Eder, Nicholson, et al., 2021). We hypothesize that between-subject variation in ethnocentrism can be predicted better than by a trivial predictor. In particular, we expect that higher pathogenic and existential threat, higher fear and vulnerability (assuming a causal interaction) and less sexual behavior (assuming a non-causal interaction) would predict higher levels of ethnocentrism.

\section{METHODS}

\section{Participants, Procedure, and Timeframe}

The sample for this study consisted of 333 adult participants from across Europe (mean age= 29.18, $\mathrm{SD}_{\text {age }}=10.95,218$ female): Austria (40\%), Poland (31\%), Spain (16\%), and Czech Republic (7\%). Additionally, 28 participants residing in other countries filled in surveys. $68 \%$ of participants were in committed relationships at the start of the study in March 2020, 35\% had children, and only $8 \%$ lived entirely alone. Moreover, $44 \%$ of all participants were still allowed to leave the house to go to work at this time. Figure 1 illustrates how participants were affected by the pandemic in terms of economic losses and infections in their immediate social sphere (Fig. 1B), as well as important psychological variables with regards to the pandemic, such as the self-assessed fear of the virus and their satisfaction with the political measures taken (Fig. 1A).

Participants were recruited over social media and completed our survey via the online platform SoSciSurvey (www.soscisurvey.de). As part of another project, participants had the option to complete questionnaires on a weekly basis over the duration of seven weeks in spring 2020, precisely as lockdown restrictions in response to the COVID-19 pandemic were first introduced in Europe. During these seven weeks, only two surveys were relevant for the current study, which were completed four weeks apart $\left(t_{1}: 23.03 .2020\right.$ until 29.03.2020, $n_{1}=280 ; t_{2}$ : 20.04.2020 until 26.04.2020, $\mathrm{n}_{2}=200$ ). Only participants who completed the scales at both points in time were included in the analysis of the stability of IWAH and PVD over the course of this crisis $(n=153)$, independent of other (e.g. demographic) missing data; and only datapoints with no missing data could be included in the prediction of inter-individual differences in IWAH, where the models accounted for the fact that some participants contributed two, some only one full datapoint.

Life in all the participating countries was severely influenced by the spread of SARS-CoV-2 during the observed period, where crucially, the spread of the virus, COVID-19 mortality and governmental responses all differed markedly between the states and over time (cf. Eder, Steyrl, et al., 2021 [Fig 1]; Petherick et al., 2020; see also www.osf.io/m26zy/). 

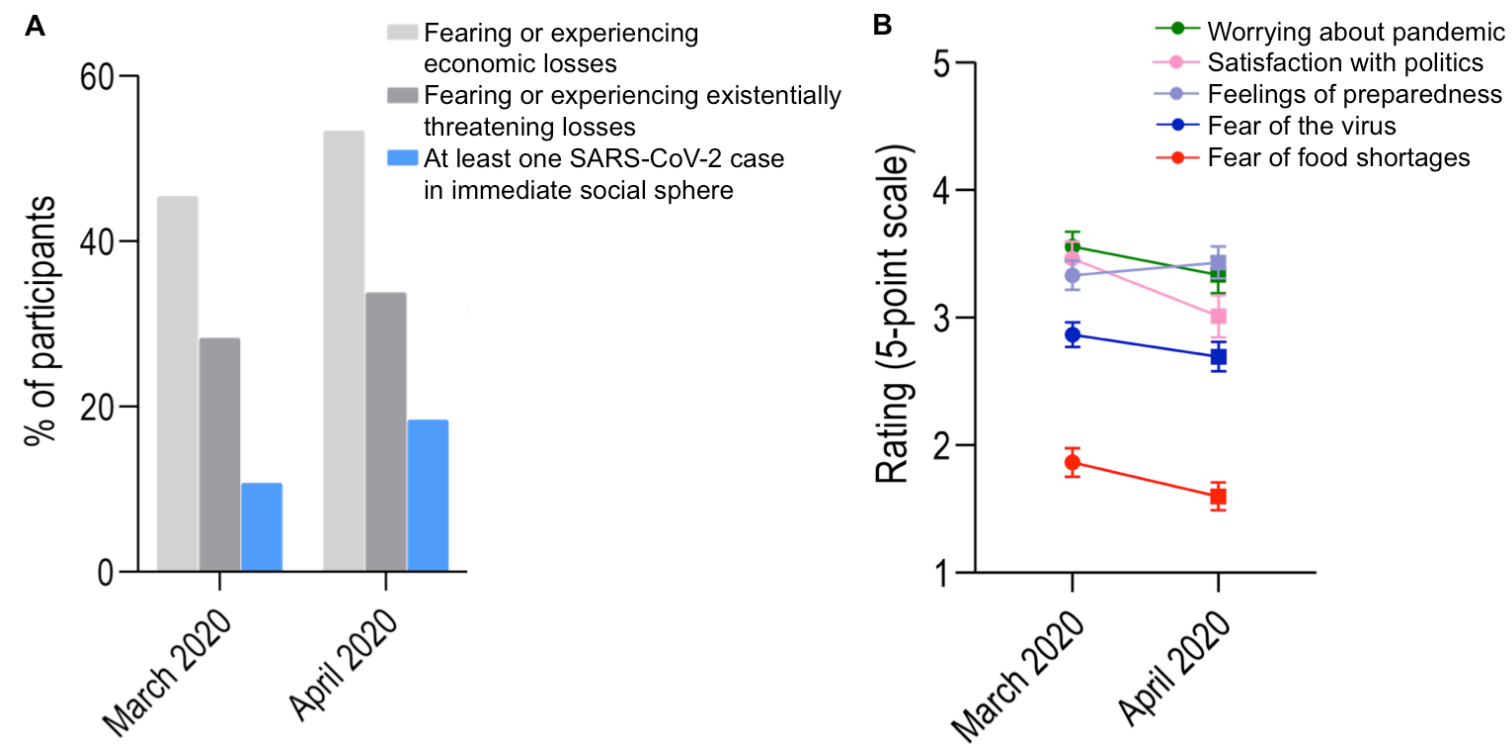

Figure 1: Changes in self-reported key variables with respect to the pandemic between the first and second survey. (A) Percentage of individuals who reported to probably experience losses in income (light grey) and to probably experience existentially threatening economic losses (grey), as well as percentage of participants who had experienced at least one SARS-CoV-2 infection in their immediate social sphere (blue). (B) Worries about the pandemic and its consequences (green), satisfaction with the governmental reactions (pink), feelings of personal preparedness for the pandemic (purple), average fear of the virus (blue), and fear of shortages in food supply (red), as rated on a 5-point Likert scale. Means and 95\% CI are depicted.

\section{Input Variables}

Our target variable was the Identification with all Humanity Scale (IWAH, McFarland et al., 2012; Cronbach's alpha between .793 and .915 in our four national samples). To obtain a single value for identification with all humanity relative to the other values, we report the 'IWAH-score', which is the standardized residual for each participant after regressing identification with all humanity against the two ingroup measures 'nation' and 'community' (see McFarland et al., 2012). Furthermore, participants completed the Perceived Vulnerability to Disease Scale (PVD, Duncan et al., 2009), which consists of the subscales 'infectability' (measuring perceived susceptibility to infectious diseases, Cronbach's alpha $=.925$ ) and 'germ aversion' (measuring aversion towards situations that might facilitate potential transmission of pathogens, Cronbach's alpha $=.703$ ). The subscales have been shown to relate to different social implications, since germ aversion is a better predictor of negative connotations with obese individuals (Park et al., 2007), and infectability correlates more with negative attitudes towards signs of old age (Duncan \& Schaller, 2009). Importantly, both factors might signal compromised immunocompetence (Duncan \& Schaller, 2009, Martí et al., 2001). Moreover, higher scores on the subscale germ aversion has been specifically linked to moral values that facilitate tight ingroup-binding (Makhanova et al., 2019).

As a measure of adult attachment security, participants completed the Experiences in Close Relationships Revised Scale (ECR-R, Fraley et al., 2000; Polish version: Lubiewska et al, 2016; 
Czech version: Cígler et al, 2019; Spanish version modified from: Fernández-Fuertes et al, 2011; Cronbach's alpha $=.917$ [subscale avoidance] and .920 [subscale anxiety]).

If no validated translation was available, the questionnaires were translated by a native speaker and reviewed by another native speaker. The translations of both the IWAH and PVD to German, Spanish, Polish and Czech as used in this study, including values regarding their internal consistency are available via the Open Science Framework: www.osf.io/2a4rc/.

We further surveyed fear of the virus, defined here as the fear of (i) getting infected as well as the perceived threat to (ii) the participants and to (iii) people who are emotionally close to them (5-point Likert scale, Cronbach's alpha $=.671$; supplementary models using the individual variables as separate predictors can be found in the OSF project: www.osf.io/r54p2/), as well as sexual behavior (levels of sexual satisfaction, amount of sexual encounters) and physical contact to other persons (touch). Moreover, we asked if the crisis and the political measures taken are perceived as economically threatening to the participant, and if they were worried about shortages and insecurities in food supplies. Demographic information included gender, sexual orientation, relationship/family status, and country of residence. As environmental factors, we included confirmed cases and deaths per million citizens for each week and country (Sources: Eurostat 2020; Hale et al., 2020), as well as an index describing the stringency of governmental measures in response to the pandemic (Petherick et al., 2020). Figure 2 provides an overview of all collected variables.

\section{Analysis}

We fit two types of machine learning models to predict IWAH: The LASSO (least absolute shrinkage and selection operator, Tibshirani, 1996), which is constricted to linearity, and the decision-tree based Extremely Randomized Trees (ERT, Geurts et al., 2006, splitting criterion: Friedman MSE). The models were evaluated with nested stratified cross-validation (90/10, 100 repeats each). This means that the models were trained on changing subsets of the data and subsequently tried to predict the target variable in those data that were new to the models. Subsequently, the performance of these models was compared to the predictions made by a trivial predictor (using the mean of all values as a prediction). The predictive value of the individual input features is assessed as their permutation feature importance (Breiman, 2001).

In addition to the machine learning analyses, paired Bayesian group comparisons between participant's first completion of the questionnaire and their final completion were calculated.

Machine learning analyses were conducted in Python 3.7.7. using the machine learning library Scikiit-Learn (0.22.2. , Pedregosa et al., 2011); descriptive analyses and group comparisons were conducted in IBM SPSS Statistics (version 25.0) and R (R Core Team, 2017); the software GraphPad PRISM (version 8.0) was used to generate plots.

\section{RESULTS}

\section{Predicting Identification with all Humanity (IWAH)}

Neither a linear nor a non-linear model taking into account variables such as country characteristics, PVD and mean fear could predict IWAH scores significantly better than a trivial predictor (LASSO: $\mathrm{R}^{2}{ }_{\text {avg }}=0.00, p=.403$; Extremely randomized trees [ERT]: $\mathrm{R}^{2}{ }_{\text {avg }}=-0.17, p=1$; $\mathrm{N}_{\text {trials }}=280, \mathrm{~N}_{\text {participants }}=168$ ). Moreover, the predictive value of all the individual input factors (measured by permutation feature importance) was close to zero in most models, where sexual 
orientation and female sex had the highest variance in permutation feature importance across models

(Figure 2).

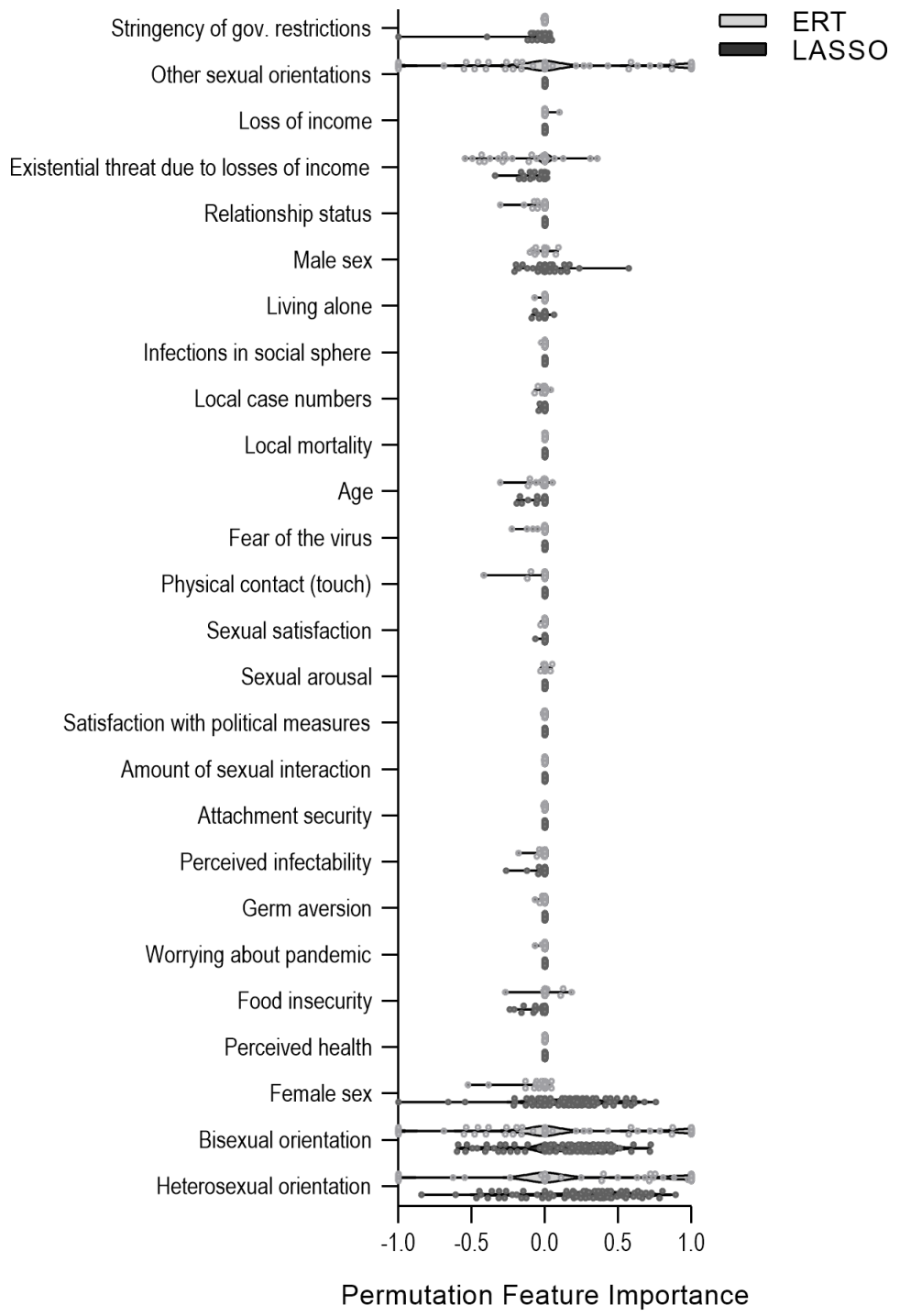

Figure 2: Figure 2: Permutation feature importance values of all input variables violin-plotted over all 100 models for both model types (LASSO/Extremely Randomized Trees). Some one-hot encoded, mutually exclusive categories with zero feature importance have been overlaid for a better overview.

\section{Decreasing germ aversion, but no systematic differences in IWAH}

Both the IWAH and PVD measures were presented at two different points in time: Once in March 2020, and three to four weeks later in April 2020. IWAH-scores did not systematically differ between these two measurements. This holds true for the 'IWAH-score' as well as for the categories 'community', 'nation', and 'all humanity' separately (IWAH-score: mean difference of - 
$.02, B F_{01}=13, N=152$; shared variance $=80.08 \%$; Subscores: mean difference less than one point each, $\left.B F_{01 \text { COMM. }}=4, B F_{01 \text { NATION }}=5, B F_{01 \text { A.H. }}=14, N=157\right)$.

For the PVD, paired group comparisons revealed no differences over time in the subscale infectability (mean decrease by $1.57 \%, B F_{01}=7.945, N=156$; shared variance $=84.27 \%$ ) but positive evidence for a slight decrease in the subscale germ aversion (mean decrease by $3.36 \%$, $B F_{01}=0.288, N=156$; shared variance $=70.90 \%$ ).

\section{DISCUSSION}

The primary aim of this study was to predict inter-individual differences in identification with all humanity (in relation to nationalistic and community-based identification; IWAH) based on perceived and actual threat during the COVID-19 pandemic, and to explore the predictive value of these variables. Further, we wanted to assess the stability of both IWAH and perceived vulnerability during the first curfews in response to the pandemic.

To do so, we surveyed 333 individuals from four European states with varying viral spread, mortality, and governmental responses in March and April 2020, when the first lockdown restrictions in response to the COVID-19 pandemic were introduced and phased out.

\section{Predicting inter-individual differences in ethnocentric orientations}

Despite the use of robust machine learning models which capture complex interactions between different input variables, these models did not predict inter-individual differences in ethnocentric orientations better than a trivial predictor. As such, our findings do not provide support for predictions derived from the parasite model of democratization and the parasite-stress theory of sociality, where an influence of pathogenic threat or the fear of that threat would be expected. According to this theoretical framework, lower levels of pathogens eventually lead to more liberal attitudes, possibly mediated by lowered ethnocentrism (Thornhill et al., 2009). In line with these theories, previous studies have linked conservatism and narrow group-binding values with disgust sensitivity or germ aversion (Helzer \& Pizarro, 2011; Makhanova et al., 2019; Shook et al., 2017; Terrizzi et al., 2013). However, some studies showed that pathogen avoidance does not relate to suspicion towards outgroups only, but more broadly towards people in general, and that it is generalized social trust that has a direct relationship with disease avoidance (Aarøe et al., 2016). Since the IWAH measure captures identification with different groups in relation to each other (McFarland et al., 2012), it might not capture effects that concern generalized social believes, which are independent of in- and outgroups. Additionally, identification with all humanity as a social identity is conceptually different from generalized trust, although there is a complex relationship between generalized trust in and identification with social and ethnic groups (see Montoya \& Pittinsky, 2011; Stets \& Fares, 2019).

Moreover, a growing body of literature has not been able to replicate the influence of pathogenic threat on conservative attitudes, in particular ingroup favoritism (Hadley \& Hruschka, 2017). It has been argued that such results may only hold for WEIRD populations or that other variables of environmental insecurity may hold more influence (Currie, \& Mace, 2012; Hadley \& Hruschka, 2017). Nonetheless, the variables 'loss of income due to the pandemic' and 'existentially threatening economic losses' had no more predictive value than variables estimating the viral spread in our WEIRD European samples. Possibly, the immediate promises of European governmental aids to compensate these losses (Danielli et al., 2020; International Monetary Fund, 2021) might have attenuated such effects (cf. Hruschka et al., 2014). 
Notably, identification with all humanity is a form of social identity and has been proposed to encompass a broader and mature meaning of global identification (McFarland et al., 2012), as opposed to measures of ethnocentrism that closely resemble xenophobia. Despite a correlation between these variables (Hamer et al., 2019), this conceptual difference in measurements complicates a direct comparison to studies measuring xenophobia or conservative moral values in general.

Other reasons that our study may not have captured influences of our predictors on ethnocentrism may include the specific points in time where data were collected, as the situation during the first curfews in response to the COVID-19 pandemic is not directly comparable to any previous studies. Further, the effects may have been too small to be detected by machine-learning analyses at our sample size, or participants may have answered randomly. The same methods using the same data were however sensitive enough to detect other associations (see Eder, Nicholson, et al., 2021), thus ruling out random answering, and effects of viral threats on ingroup binding norms have been observed at 95\% power in smaller samples (Makhanova et al., 2019).

\section{Stability of identification with all humanity and perceived vulnerability to disease}

In addition to exploring environmental and psychological predictors of IWAH, we compared IWAH and PVD scores at the beginning and towards the end of the first European lockdown restrictions.

Despite the unstable times, our measurement of ethnocentric orientation did not differ systematically between the beginning and the end of the lockdown on a group level. This is in line with other findings in relation to the COVID-19 pandemic: Hamer and colleagues (2021) similarly found no changes in identification with all humanity during the pandemic in Poland. Thus, not only could we not predict inter-individual differences in this measure based on psychological and external variables related to the pandemic, but the emerging evidence also suggests that the expected overall shift towards identifications with narrower ingroups may not have occurred in response to the pandemic.

Interestingly, however, germ aversion showed a slight decrease over the course of the first European responses to the COVID-19 pandemic. As opposed to disgust sensitivity, germ aversion specifically concerns infectious diseases (Duncan et al., 2009), and as such, was the only measurement related to pathogenic threat that showed a systematic difference over the period we observed. This may be unexpected and possibly maladaptive as infection numbers were rising over the study period, and the behavioral immune system should respond to higher environmental pathogenic threat with heightened pathogen disgust (cf. Schaller \& Park, 2011). However, being overly sensible to pathogen threat is no longer adaptive in an environment with an abundance of pathogens, and lowered disgust sensitivity may help coping with such circumstances (Batres \& Perrett, 2020). Moreover, another study conducted in a comparable time frame surprisingly found a negative association between pathogen disgust and SARS-CoV rates (Hlay et al., 2021), an association which has post-hoc been replicated (see www.osf.io/snauq). All of these findings indicate the complexity of these emotional systems beyond intellectually appealing theories.

\section{Conclusion}

This study presented findings on the stability of identification with all humanity, perceived infectability, and germ aversion during lockdown phases of the COVID-19 pandemic in Europe. We further investigated ethnocentric orientations as a potential link between more conservative 
attitudes in response to pathogenic threat (see Karwowski et al., 2020), and explored a variety of predictors of ethnocentric orientations. To do so, we utilized machine-learning models aiming to predict ethnocentrism based on intra-individual and environmental factors. Importantly, these models are capable of detecting complex interactions between different input factors, and they have uncovered predictors of other psychological variables within the same sample. Even so, differences in ethnocentrism could not be predicted from our machine learning models that incorporated pathogenic threat, fear, perceived vulnerability, economic threats, sexual behavior, and attachment security. Therefore, our results are not in line with the large body of literature postulating connections between pathogen levels, ethnocentrism, and a variety of factors linked to liberal attitudes, nor do we find an influence of economic threats. Indeed, our findings indicate that people do not identify with narrower ingroups in response to a pandemic, and we conclude that postulated changes with regards to such variables might be less drastic than predicted by theory. Hence, our findings add to the growing body of literature demanding caution when interpreting the relationship between ingroup bias and pathogen stress (e.g. Ross \& Winterhalder, 2016). As more data is collected during the COVID-19 pandemic, follow-up studies might contribute to further clarifying the relationship between these highly relevant societal and psychological variables.

\section{ACKNOWLEDGEMENTS}

We thank Edward John Noon for English-proofreading the manuscript, and Katarzyna Hamer from the Identification with all Humanity Lab for her supportive recommendations.

We would also like to thank two anonymous reviewers and the editors for their comments, which greatly contributed to improving the manuscript.

\section{FUNDING STATEMENT}

Frank Scharnowski was supported by the Swiss National Science Foundation (BSSG10_155915, 100014_178841,32003B_166566), the Foundation for Research in Science and the Humanities at the University of Zurich (STWF-17-012), and the Baugarten Stiftung.

\section{ETHICAL STATEMENT}

Data collection and analysis was conducted in accordance with the 1964 Helsinki declaration and later amendments, as well as national guidelines. Potentially intimate questions were additionally approved by the Institutional Review Board of Charles University, Faculty of Science. 


\section{REFERENCES}

Aarøe, L., Osmundsen, M., \& Petersen, M. B. (2016). Distrust As a Disease Avoidance Strategy: Individual Differences in Disgust Sensitivity Regulate Generalized Social Trust. Frontiers in Psychology, 7. DOI

Altemeyer, B. (1996). The authoritarian specter. Harvard University Press.

Batres, C., \& Perrett, D. I. (2020). Pathogen disgust sensitivity changes according to the perceived harshness of the environment. Cognition and Emotion, 34(2), 377-383. DOI

Breiman, L. (2001). Random Forests. Machine Learning 45, 5-32. DOI

Burnham, B. R. (2020). Are liberals really dirty? Two failures to replicate Helzer and Pizarro's (2011) study 1, with meta-analysis. Journal of Personality and Social Psychology, 119(6). DOI

Cashdan, E. (2001). Ethnocentrism and xenophobia: A cross-cultural study. Current Anthropology, 42(5), 760-764. DOI

Cashdan, E., \& Steele, M. (2013). Pathogen prevalence, group bias, and collectivism in the standard crosscultural sample. Human Nature, 24(1), 59-75. DOI

Cígler, H., Cvrčková, A., Daňsovác, P., Hašto, J., Charvát, M., Ježek, S., ... Seitl, M. (2019). Experiences in close relationships: České verze metod pro měření vazby vycházející z dotazníku ECR. Epsychologie, 13(4) 57-74. DOI

Currie, T. E., \& Mace, R. (2012). Analyses do not support the parasite-stress theory of human sociality. Behav Brain Sci, 35(2), 83-85. DOI

Danielli, S., Patria, R., Donnelly, P., Ashrafian, H., \& Darzi, A. (2020). Economic interventions to ameliorate the impact of COVID-19 on the economy and health: an international comparison. Journal of Public Health, 43(1). DOI

Duncan, L. A., \& Schaller, M. (2009). Prejudicial attitudes toward older adults may be exaggerated when people feel vulnerable to infectious disease: Evidence and implications. Analyses of Social Issues and Public Policy, 9(1), 97-115. DOI

Duncan, L. A., Schaller, M., \& Park, J. H. (2009). Perceived vulnerability to disease: Development and validation of a 15-item self-report instrument. Personality and Individual Differences, 47(6), 541-546. DOI

Eder, S.J., Steyrl, D., Stefanczyk, M.M, Pieniak, M., Martínez Molina, J., Pešout, O., ... Nicholson, A. (2021). Predicting fear and health during the COVID-19 pandemic using machine learning: A cross-national longitudinal study. PLOS ONE, 16(3), e0247997. DOI

Eder, S. J., Nicholson, A., Stefanczyk, M., Pieniak, Martínez Molina, J. M., Pešout, O., .. Steyrl, D. (2021). Securing your relationship: Quality of intimate relationships during the COVID-19 pandemic can be predicted by attachment security. Frontiers in psychology. 12:647956. DOI

Eurostat (2020, April 23 $3^{\text {rd }}$ ). Population on 1 January (online data code:TPS00001). Retrieved from https://ec.europa.eu/eurostat/databrowser/view/tps00001/default/table?lang=en

Faulkner, J., Schaller, M., Park, J. H., \& Duncan, L. A. (2004). Evolved disease-avoidance mechanisms and contemporary xenophobic attitudes. Group Processes \& Intergroup Relations, 7(4), 333-353. DOI

Fernández-Fuertes, A. A., Orgaz, B., Fuertes, A., \& Carcedo, R. (2011). La evaluación del apego romántico en adolescentes españoles: validación de la versión reducida del Experiences in Close Relationships-Revised (ECR-R). Anales de psicología, 27(3), 827-833. DOI

Fincher, C.L. and Thornhill, R. (2012) Parasite-stress promotes in-group assortative sociality: the cases of strong family ties and heightened religiosity. Behavioral and Brain Sciences, 35(2), 61-79. DOI

Fraley, R. C., Waller, N. G., \& Brennan, K. A. (2000). An item response theory analysis of self-report measures of adult attachment. Journal of Personality and Social Psychology, 78(2), 350. DOI

Geurts, P., Ernst, D., \& Wehenkel, L. (2006). Extremely randomized trees. Machine learning, 63(1), 3-42. $\underline{\mathrm{DOI}}$

Hadley, C., \& Hruschka, D. (2017). Stability and change in in-group mate preferences among young people in Ethiopia are predicted by food security and gender attitudes, but not by expected pathogen exposures. Human Nature, 28(4), 395-406. DOI 
Hale, T., Webster, Anna Petherick, Toby Phillips, and Beatriz Kira (2020, May 18 $\left.{ }^{\text {th }}\right)$. Oxford COVID-19 Government Response Tracker, Blavatnik School of Government. https://www.bsg.ox.ac.uk/research/ research-projects/coronavirus-government-response-tracker

Hamer, K., Baran, M., Marchlewska, M., Kaniasty, K. (2021). Zmiany w identyfikacjach społecznych, myśleniu spiskowym, obawach, dobrostanie i zachowaniach Polaków podczas pierwszej fali pandemii COVID-19. [Changes in social identifications, conspiracy thinking, fears, well-being and behavior of Poles during the first wave of the COVID-19 pandemic]. In J. Paluchowski, L. Bakiera (eds.) (in print). Psychospoteczny obraz pierwszej fali pandemii COVID-19w Polsce. [Psychosocial image of a first wave of COVID-19 pandemic in Poland]. Poznań: Wydawnictwo Naukowe UAM.

Hamer, K., McFarland, S., \& Penczek, M. (2019). What lies beneath? Predictors of identification with all humanity. Personality and Individual Differences, 141, 258-267. DOI

Hammond, R. A., \& Axelrod, R. (2006). The evolution of ethnocentrism. Journal of Conflict Resolution, 50(6), 926-936. https://dx.doi.org/10.1177/0022002706293470

Helzer, E. G., \& Pizarro, D. A. (2011). Dirty Liberals!: Reminders of Physical Cleanliness Influence Moral and Political Attitudes. Psychological Science, 22(4), 517-522. DOI

Hlay, J. K., Albert, G., Batres, C., Richardson, G., Placek, C., Arnocky, S., ... \& Hodges-Simeon, C. R. (2021). The evolution of disgust for pathogen detection and avoidance. Scientific Reports, 11(1), $1-12$. DOI

Hruschka, D., Efferson, C., Jiang, T., Falletta-Cowden, A., Sigurdsson, S., McNamara, R., ... \& Henrich, J. (2014). Impartial institutions, pathogen stress and the expanding social network. Human Nature, 25(4), 567-579. DOI

Hruschka, D. J., \& Henrich, J. (2013). Economic and evolutionary hypotheses for cross-population variation in parochialism. Frontiers in Human Neuroscience, 7, 559. DOI

Inbar, Y., Pizarro, D., Iyer, R., \& Haidt, J. (2012). Disgust Sensitivity, Political Conservatism, and Voting. Social Psychological and Personality Science, 3(5), 537-544. DOI

Inglehart, R., Moaddel, M., \& Tessler, M. (2006). Xenophobia and in-group solidarity in Iraq: A natural experiment on the impact of insecurity. Perspectives on Politics, 4(3), 495-505. DOI

International Monetary Fund [IMF] (2021, March 7th). Policy Responses to COVID-19. IMF. https:// www.imf.org/en/Topics/imf-and-covid19/Policy-Responses-to-COVID-19

Karwowski, M., Kowal, M., Groyecka, A., Białek, M., Lebuda, I., Sorokowska, A., \& Sorokowski, P. (2020). When in danger, turn right: Does covid-19 threat promote social conservatism and right-wing presidential candidates. Human Ethology, 35, 37-48. DOI

Landy, J. F., \& Goodwin, G. P. (2015). Does incidental disgust amplify moral judgment? A meta-analytic review of experimental evidence. Perspectives on Psychological Science, 10(4), 518-536. DOI

Lubiewska, K., Gogowska, K., Mickiewicz, K., Wyrzykowska, E., Winiewski, C., Izdebski, P., \& Staffa, U. (2016). Skala Experience in Close Relationships-Revised: Struktura, Rzetelno oraz Skrócona Wersja Skali w Polskiej Próbie. Psychologia Rozwojowa, 21(1), 49-63. DOI

Makhanova, A., Plant, E. A., Monroe, A. E., \& Maner, J. K. (2019). Binding together to avoid illness: Pathogen avoidance and moral worldviews. Evolutionary Behavioral Sciences, 13(2), 182. DOI

Martí, A., Marcos, A., \& Martínez, J. A. (2001). Obesity and immune function relationships. Obesity reviews, 2(2), 131-140. DOI

McFarland, S., Webb, M., \& Brown, D. (2012). All humanity is my ingroup: A measure and studies of identification with all humanity. Journal of personality and social psychology, 103(5), 830-853. DOI

Mikulincer, M., \& Shaver, P. R. (2001). Attachment theory and intergroup bias: Evidence that priming the secure base schema attenuates negative reactions to out-groups. Journal of Personality and Social Psychology, 81(1), 97-115. DOI

Montoya, R. M., \& Pittinsky, T. L. (2011). When increased group identification leads to outgroup liking and cooperation: The role of trust. The Journal of social psychology, 151(6), 784-806. DOI

Navarrete, C. D., \& Fessler, D. M. (2006). Disease avoidance and ethnocentrism: The effects of disease vulnerability and disgust sensitivity on intergroup attitudes. Evolution and Human Behavior, 27(4), 270-282. DOI 
Neuliep, J. W., \& McCroskey, J. C. (1997). The development of a US and generalized ethnocentrism scale. Communication Research Reports, 14(4), 385-398. DOI

Nowak, M. A. (2006). Five rules for the evolution of cooperation. Science, 314(5805), 1560-1563. DOI

Pan, X., Nau, D., \& Gelfand, M. (2020). Cooperative norms and the growth of threat: Differences across tight and loose cultures. In: 2020 7th International Conference on Behavioural and Social Computing (BESC) (pp. 1-6). IEEE. DOI

Park, J. H., Schaller, M., \& Crandall, C. S. (2007). Pathogen-avoidance mechanisms and the stigmatization of obese people. Evolution and Human Behavior, 28(6), 410-414. DOI

Pedregosa, F., Varoquaux, G., Gramfort, A., Michel, V., Thirion, B., Grisel, O., ... Duchesnay, E. (2011). Scikit-learn: Machine learning in Python. Journal of Machine Learning Research, 12, 2825-2830.

Pettigrew, T. F. (2004). Ethnocentrism. In K. Kempf-Leonard (Ed.), Encyclopedia of Social Measurement. San Diego, CA: Academic

Petherick, A., Hale, T., Phillips, T., \& Webster, S. (2020, May 6th). Variation in government responses to COVID-19. Blavatnik school working paper. Retrieved from https://www.bsg.ox.ac.uk/research/ publications/variation-government-responses-covid-19

Roos, P., Gelfand, M., Nau, D., \& Lun, J. (2015). Societal threat and cultural variation in the strength of social norms: An evolutionary basis. Organizational Behavior and Human Decision Processes, 129, 14-23. DOI

Ross, C. T., \& Winterhalder, B. (2016). A hierarchical bayesian analysis of parasite prevalence and sociocultural outcomes: The role of structural racism and sanitation infrastructure. American Journal of Human Biology, 28(1), 74-89. DOI

Schaller, M., \& Park, J. H. (2011). The behavioral immune system (and why it matters). Current Directions in Psychological Science, 20(2), 99-103. DOI

Schnall, S., Haidt, J., Clore, G. L., \& Jordan, A. H. (2015). Landy and Goodwin confirmed most of our findings then drew the wrong conclusions. Prospect Psychol Sci., 10(4). DOI

Shook, N. J., Ford, C. G., \& Boggs, S. T. (2017). Dangerous worldview: A mediator of the relation between disgust sensitivity and social conservatism. Personality and Individual Differences, 119, 252-261. $\underline{\text { DOI }}$

Stets, J. E., \& Fares, P. (2019). The effects of race/ethnicity and racial/ethnic identification on general trust. Social Science Research, 80, 1-14. DOI

Terrizzi Jr, J. A., Shook, N. J., \& McDaniel, M. A. (2013). The behavioral immune system and social conservatism: A meta-analysis. Evolution and Human Behavior, 34(2), 99-108. DOI

Thornhill, R., Fincher, C. L., \& Aran, D. (2009). Parasites, democratization, and the liberalization of values across contemporary countries. Biological Reviews, 84(1), 113-131. DOI

Tibshirani, R. (1996). Regression shrinkage and selection via the lasso. Journal of the Royal Statistical Society: Series B (Methodological), 58(1), 267-288. DOI

Tybur, J. M., Inbar, Y., Aarøe, L., Barclay, P., Barlow, F. K., De Barra, M., ... \& Žeželj, I. (2016). Parasite stress and pathogen avoidance relate to distinct dimensions of political ideology across 30 nations. Proceedings of the National Academy of Sciences, 113(44), 12408-12413. DOI

Tybur, J. M., Inbar, Y., Güler, E., \& Molho, C. (2015). Is the relationship between pathogen avoidance and ideological conservatism explained by sexual strategies? Evolution and Human Behavior, 36(6), 489-497. DOI

Van de Vliert, E., \& Postmes, T. (2012). Climato-economic livability predicts societal collectivism and political autocracy better than parasitic stress does. Behavioral and Brain Sciences, 35(2), 94. DOI

Zhai, Y., \& Du, X. (2020). Mental health care for international Chinese students affected by the COVID-19 outbreak. The Lancet Psychiatry, 7(4), e22. DOI 